\title{
Disaggregation of Gendered Differences in Retirement Planning in Urban Ghana
}

\author{
Delali Adjoa Dovie \\ University of Ghana - dellsellad@gmail.com
}

\begin{abstract}
The paper investigates gendered retirement planning, using quantitative and qualitative datasets obtained from formal and informal sector workers $[n=442]$. The analyses show that the majority of workers (45.4\%) opined that women's retirement preparations are tied to men's, particularly housewives and married ones, reasoning that men are heads of their households. This includes women's desire to be and/or live closer to their partners. Whilst women's preparations may be tied to men's, men often plan for retirement with the support of their spouses. An extent of independence between men and women regarding retirement planning and different levels of societal responsibilities pertains.

These are two independent people with different responsibilities, preferences, needs and reasons. However, women are less likely than men to actively plan for retirement. This is inhibited by women's low income flows compared to their male counterparts. Yet, women need to institute more plans than men because women most often do not have social security and live relatively longer. Significantly, what prompts women to plan differs from what motivates men. This provides a reinforcement of the importance of considering gender when seeking to understand the variables that predict retirement planning tendencies, and might contribute to successfully attaining financial security.
\end{abstract}

Keywords: Gender, retirement aspirations, retirement planning, socialization, longevity, women's retirement plans.

\section{Desagregação das Diferenças de Género no Planeamento da Reforma no Gana Urbano}

\begin{abstract}
Sumário
Este artigo investiga as diferenças no uma técnica de amostragem em várias fases. planeamento da reforma em função do género entre os trabalhadores do sector formal e informal. Método: Foram utilizados conjuntos de dados quantitativos e qualitativos. A amostra [n=442] foi selecionada utilizando As análises mostram que a maioria dos trabalhadores (45.4\%) considerou que os preparativos para a reforma das mulheres estão ligados aos dos homens, em especial as casadas e as domésticas, por razões relacionadas com
\end{abstract}




\section{Disaggregation of Gendered Differences in Retirement Planning in Urban Ghana}

o facto de os homens serem chefes de família. Isto inclui desejo das mulheres de estarem e/ ou viverem mais próximas dos seus parceiros. Embora os preparativos para a reforma das mulheres possam estar ligados aos dos homens, estes planeiam muitas vezes com o apoio dos seus cônjuges. Existe uma certa independência entre homens e mulheres em matéria de planeamento da reforma e diferentes níveis de responsabilidades societais. Trata-se de duas pessoas independentes com responsabilidades, preferências, necessidades e razões diferentes. Contudo, as mulheres têm menos probabilidades do que os homens de planear ativamente a reforma. Isto é inibido pelos fluxos de baixos rendimentos das mulheres, em comparação com os seus homólogos masculinos. No entanto, as mulheres precisam de instituir mais planos do que os homens porque, na maioria das vezes, as mulheres não têm segurança social e vivem relativamente mais tempo. Significativamente, as razões que levam as mulheres a planear são diferentes daquelas que motivam os homens. Isto reforça a importância de considerar o género, quando se procura compreender as variáveis que predizem as tendências de planeamento da reforma. Tal garantiria, em particular, uma segurança financeira bem sucedida.

Palavras-chave: Género, planeamento da reforma, longevidade, planos de reforma das mulheres.

\section{INTRODUCTION}

Ensuring an economically secure and stable post-retirement life requires planning in advance during pre-retirement life and/or to the attainment of the retirement age. Satisfaction in retirement years is clearly associated with pre-retirement planning. However, inadequate or incomplete pre-retirement preparation may culminate in poverty in old age among older people with resources, sufficient for surviving on daily basis, yet, little or nothing for amenities (Phua \& McNally, 2008). Retirement preparation is often affected by such factors as socio-economic status, family responsibilities, personal history, cultural and generational orientation towards life (Duflo \& Saez, 2003; Phua \& McNally, 2008), including insufficient retirement planning information (Dovie, 2017, 2018a, 2018b, 2019a) among men and women. 
Retirement planning denotes the diverse preparations and the associated preparation portfolios workers institute during active service or working life phase in anticipation of life after retirement (Agbobli, 2011; Novak, 2006). Critical issues to be taken into consideration in planning for post-retirement life are the weakening of traditional social support systems, increased life expectancy (Zaidi, 2015), and the lack of formal social support infrastructure (Aboderin, 2006; Dovie, 2018a, 2018b, 2019b; Holzmann \& Stiglits, 2001).

"Poor financial planning for retirement is reported to be a major problem among formal and informal sector workers and may compound overdependence documented among elderly individuals" (de-Graft Aikins et al., 2016, p.176). Further, not planning towards retirement may engender vulnerability to economic dependence in later life. In essence, "favourable attitudes towards retirement are associated with planning, counselling, personal discussions and exposure to news media presentations about retirement" (Barrow, 1986, p. 169) including social media (Dovie, 2019c). To live a successful or trouble free retirement life is to plan for it now.

Further, Forster and Walker (2013) and Paz and colleagues (2018) have argued that a gendered analysis of active ageing is needed, given the gender gap in life expectancy, health, income and social context. Due to these gender gaps, old-age exclusion could follow a very different pattern for men and women.

Among other things, retirement planning is critical to ensuring financial security at older ages for men and women, yet few studies have explicitly examined what it means to plan for retirement along gender lines. To contribute to research on preretirement planning, this study examines gendered retirement planning among men and women in the formal and informal sectors of the Ghanaian economy. Survey and interview data was used to understand the perspectives of these women and men on gendered retirement planning. Specifically, the association between women's and men's retirement plans is explored and how they prepare towards both financially and non-financially sound post-retirement life, including the strategies they used in doing so. These issues remain under-researched and are here given full consideration. It is noteworthy that retirement preparation and retirement planning are used interchangeably in this paper.

\section{Involvement in work}

Recent data provided by the Ghana Living Standards Survey, Six (GLSS 6) amply demonstrates that the current structure of the labor force in Ghana is similar to that of the pre-colonial/colonial period. As it was in the past, the majority of Ghanaians 


\section{Disaggregation of Gendered Differences in Retirement Planning in Urban Ghana}

are employed in the agricultural sector. Forty-five percent of all the employed persons, who are 15 years and older, are employed in the agriculture sector. Gender differences can also be seen in the sector. Females constituted 48\%, while the proportion of males was $41 \%$ (Tsikata \& Darkwah, 2014). Moreover, in that sector, females are less likely to be self-employed with employees.

However, it is worth noting that notwithstanding the fact that the majority of Ghanaians are employed in the agricultural sector, discussions regarding the agriculture sector are beyond the scope of this paper.

Laborforce by occupation has the following disposition(s): agriculture $-44.7 \%$ (note that agriculture encompasses farming, fishing and forestry); industry (manufacturing) - 14.4\% and services 40.9\% (CIA World Factbook, 2019). After Ghana gained independence in 1957, the government led by Nkrumah launched an industrialization drive that increased the share of manufacturing towards gross domestic product (GDP) from $10 \%$ to $14 \%$ in 1970 . This resulted in the creation of a relatively wide range of industrial enterprises, the largest including the Volta Aluminum Company (VALCO) smelter, saw mills and timber processing plants, cocoa processing plants, breweries, cement manufacturing, oil refining, textiles manufacturing operations and vehicle assembly plants. Most of these survived through protection. The most important manufacturing industries in Ghana entail electronics manufacturing, car manufacturing, electric car manufacturing, automatic manufacturing, cement manufacturing, aluminum smelting, food processing and small and commercial ship building. Whereas industry in Ghana accounts for approximately $25.3 \%$ of GDP, the nation's industrial production is rising at $7.8 \%$, which gives it the 38 th fastest growing industrial production in the world. Further, after rebating in 2010, Ghana's industrial sector comprises manufacturing, construction, mining and quarrying, electricity and water and sewerage (Addo, 2017).

In Ghana, the Civil Service Law, the Local Government Act, the Local Government Service Act and the National Development Planning (Systems) Act are the main legislations governing administrative decentralization. Administrative decentralization in Ghana involves ministerial restructuring and the establishment of decentralized Departments of the District Assemblies. Several sectors of the national level administration have been decentralized (Tsikpor, n.d.). Services cover government activities; communications, transportation, finance, education, health and other private endeavors that do not produce material goods (CIA World Factbook, 2019).

Baah-Boateng (2007) affirms that high levels of women's participation in the 
laborforce exist in Ghana. However, this "uniqueness masks important differences in the nature of women and men's participation rates in Ghana both in the formal and informal sectors" (Darkwah, 2014, p. 139). Prior studies articulate the fact that aspects of socio-economic status (SES) such as education, occupational status, and income are positively related to retirement planning (Schellenberg et al., 2005). Those who are more educated tend to work in higher status occupations, earn more, and can therefore make more financial provisions for retirement. Yet the relationship between gender and SES is less clear.

\section{Gender and Retirement}

There are more men than women in formally paid jobs, which, to a large extent, are more secured in terms of income, with fewer fluctuations. This is further confounded by the fact that women receive reduced incomes which culminates in lesser savings on their part and in consequence the retirement benefits. The choices individuals make today may result in extended consequences in the nearest future. The direction of the relationship between planning towards retirement and post-retirement life finds expression in the fact that the choices individuals make today may result in extended consequences in the nearest future, especially in post-retirement life.

Planning towards retirement is of tremendous importance across the gender spectrum. In other words, it is pertinent for both men and women. The process of retirement planning comprises several pillars, namely the identification and articulation of retirement aspirations, pre-retirement education (PRE), and a host of others (Dovie, 2019d). However, there are differences in planning towards retirement in terms of the sector of the economy in question, albeit formal or informal. Whereas men are more employed to a large extent in the formal sector, the reverse applies to women who predominate in the informal sector (Osei-Boateng \& Ampretwum, 2011), where job security is fragile. Further, women often easily take a break from the workforce for reasons such as child birth, caregiving to ailing spouses, children and/or parents (Barrow, 1986; Quadagno, 2002; Novak, 2006; Moody, 2010). This has implications for the regularity of their incomes, albeit their pension contributions. This may result in women becoming poorer in old age. In addition, women live longer than men.

Retirement experience varies for different classes and gender groups. This is because disadvantages in the labor force are reproduced during retirement since lower levels of post-retirement incomes are received by lower level job training and ben- 


\section{Disaggregation of Gendered Differences in Retirement Planning in Urban Ghana}

efits, including working as a civil servant in Ghana, with a great demand for dependence on public retirement funds together with social security. Women are the most affected because men have much more resources in retirement than women. In addition, post-retirement benefits are linked to income, yet women receive less income and social security (Hatch, 1990).

Mba (2010) purports that in sub-Saharan Africa, including Ghana, fertility values are 6.7 live births per woman in the early 1950s to 5.5 live births per woman by early 2000s and an expected 2.4 live births per woman by the 2045-2050 period. In a similar vein, the expectation of life at birth rose from 36.7 years in the 1950 s to 48.4 years by $2000-2005$, and is projected to peak at 68.4 years during the 2045-2050 period. Evidence from many countries suggests that women live longer than men. Also, since women marry men much older than themselves, especially in parts of Africa, they are expected to survive their husbands. As a result, more elderly women than men should be expected at older ages. WHO (2020) documents that on average women generally live longer than men by 6 to 8 years.

\section{Retirement Planning and Gender Differences}

The disparity in salaries between men and women is well established (e.g., Correll, Benard, \& Paik, 2007), as is the impact these disruptions and disparities have on retirement planning for women and the level of economic security they can achieve in their post-employment years (e.g., Angel, Jiménez, \& Angel, 2007; Orel, Ford \& Brock, 2004). Further, the different social role expectations of women also affects their financial stability. For instance, as mentioned early, women withdraw from the labor force to raise children or care for parents and retire early to be with their spouses at far greater rates than do men (Cunningham, 2007; Quadagno, 2014). Trewin and Curatola (2002) found that to maintain equity in retirement income, women need to not only save for retirement but also do so far more aggressively than men to achieve the same result. Jacobs-Lawson, Hershey, and Neukam (2004) also found gender differences in the amount of time in terms of planning for and thinking about retirement. They found that men spend more time compared to women on these activities. Hershey et al. (2007) also found that the planning behaviors of women significantly differ from those of men.

Cumulatively, research focus on gender differences in retirement planning has changed markedly across the past century as Western society has seen a shift in gender

roles with respect to work and retirement. Traditional gender roles placed work and retirement firmly in the men's domain while any research with women considered only 
their husbands' retirement. Despite women's increasing presence in the workforce since World War II, research into women's retirement, including their preparatory behaviors, did not begin in earnest until 1976 (Slevin \& Wingrove, 1995). Research over the following two decades consistently showed that women, in general, did less retirement planning than men (Atchley, 1982; Noone, Alpass, \& Stephens, 2010).

Life in general, and post-retirement life in particular, is shaped by resource availability. The amount of income received affects what individuals are able to do, including retirement planning and affordability of health care (Atchley \& Barusch, 2004). In an empirical analysis of gender differences in investment behavior, Berggren and Gonzales (2010) said that there is a prevailing notion that men and women behave differently on financial risk taking, as men prefer to take more risks when investing than women.

Men are encouraged to be more outgoing, aggressive and assertive while women are to be more sensitive and emotional. The differences in gender role socialization between men and women can be realized as one key factor of gender variation in risk tolerance. Risk taking can also be linked to the notions of aggressiveness and assertiveness in the context of managerial decision making behavior. Consistent with previous studies, using the 2007 Survey of Consumer Finances (SCF), Fisher (2010) showed that the financial saving behaviors of men and women differ. The empirical analysis of gender saving behavior depicted a relationship between risk tolerance and results of saving.

The measurement of financial retirement planning may be seen as falling into two broad categories: financial preparedness and, less formal, retirement thoughts and planning behaviors. Financial preparedness is typically assessed by pension wealth and/ or the ownership of other investments such as property, shares, and personal savings (see Clare, 2004).

It is along this trajectory that this paper sought to explore retirement planning from the viewpoint of retirement aspirations, gender related independent dynamics, interdependent dynamics, as well as attitudinal patterns among formal and informal sector workers in the process of retirement planning.

\section{THEORETICAL PERSPECTIVES}

The theoretical underpinnings to this study are taken from Atchley's (2000) retirement theory, Bandura's (1977) social learning theory and Caldwell's $(1976,2005)$ wealth flow theory. 


\section{Disaggregation of Gendered Differences in Retirement Planning in Urban Ghana}

The stages of retirement theory's pre-retirement phase (Atchley, 2000) stipulates an interplay between the development of detailed retirement aspirations and expectations that yield fairly accurate representations of the future; pre-retirement education and portfolio institution. The theory suggests that retirement planning should be pursued as an ongoing process.

One important factor directing gendered financial behavior are gender differences in socialization. Thus, there is the need to understand whether gender role in socialization contributes in determining gendered financial behaviors, as well as perceived knowledge of women's low risk tolerance and vice versa. Initially, in Bandura's (1977) social learning theory, he pointed out that people learned their own behavior by observing behaviors of the most admired or intimate people in their lives. He named modeling the process of observational learning (see also Renzetti, Curran, Maier, \& Shana, 2012). Bandura explained further that modeling allow human beings to learn more quickly and more efficiently.

The socialization process starts from childhood and continues throughout life (McNeal, 1987; Pescaru, 2019). Throughout socialization processes people develop knowledge (including financial knowledge) and skills by contacting, observing, and interacting (Pescaru, 2019; Fox, Bartholomae, \& Gutter, 2000). Knowledge, skills and attitudes obtained from the socialization process can be extended to the financial socialization process. In this sense, genders develop their financial behavior depending on their perceived stereotyped social roles and norms. The modern division of labor asks women to be unconditionally responsible for nonpaid house care work and asks men to be industrial or economic activists. Through socialization at young age, men are taught to be outgoing and achievement oriented, whereas women are taught to be emotionally oriented and reserved in their interactions with others (e.g., Fennell, Barchas, Cohen, McMahon \& Hildebrand, 1978; Pescaru, 2019). Furthermore, girls are generally socialized to respect men's power, authority and to refrain from expressions of aggressiveness or assertiveness (Greenspan, 1983). Boys, on the other hand, are typically socialized to be assertive and aggressive (Powell, 1988) on the other hand Caldwell $(1976,2005)$ underscores children's insurance value in times of parents' old age. The insurance role is more important than the investment role.

Socialization is the lifelong process of inheriting and disseminating norms, customs and ideologies, providing an individual with the skills and habits necessary for participating within his or her own society. It is the process by which human infants acquire the skills necessary to perform as functioning members of their society, a 
process that continues throughout an individual's life (Moniz, 2010; Pescaru, 2019; Purpura, 2013). The socialization process can be divided into primary and secondary socialization. Primary socialization occurs when a child learns the attitudes, values and actions appropriate to individuals as members of a particular culture. This is mainly influenced by the immediate family and friends. Secondary socialization is the process of learning what is the appropriate behavior as a member of a smaller group within the larger society. It is the behavioral patterns reinforced by socializing agents of society such as schools and workplaces (Dovie, 2019c; Moniz, 2010; Pescaru, 2019; Purpura, 2013).

Successful socialization can result in uniformity within a society. If all children receive the same socialization, it is likely that they will share the same beliefs and expectations. Individuals who internalize the norms of society are less likely to break the law or to want radical social changes. In all societies, however, there are individuals who do not conform to culturally defined standards of normalcy because they were "abnormally" socialized, which is to say that they have not internalized the norms of society. These people are usually labeled by their societies as deviant or even mentally ill (O’Neil, 2011).

\section{RESEARCH METHODS}

Tema is a typical major Ghanaian city that is privy to and epitomizes an urban setting, in which it is possible to analyze gendered retirement plans among workers. Data for this paper was collected as part of a bigger research project. This project was part of a PhD degree in Sociology, focused on the preparations of Ghanaian formal and informal sector workers towards retirement. The data collection took a cumulative period of 16 months, from October 2015 to January 2017.

\section{Subjects and Settings}

An explanatory sequential mixed methods strategy was employed in this study. Using a two-phase approach, the study gathered both quantitative and qualitative datasets. The initial quantitative phase ascertained workers' general views on retirement planning along gender dimensions. A multi-stage clustered sampling technique was used to select a sample of 442 workers aged 18-59 years utilizing the formula by Moore and McCabe (1993). An anticipated non-response was built into the survey design. Further, organi- 


\section{Disaggregation of Gendered Differences in Retirement Planning in Urban Ghana}

zations were first stratified into formal and informal sectors, after which they were then clustered into manufacturing, administrative and service organizations. Out of these, the administrative and service units were randomly selected. From these, individual workers were also randomly selected. Thus, the total population of Tema according to Ghana Statistical Service (2014) is 292,772, out of which 135,640 are employed, and it was from this population that the sample for the study was selected. The second phase sought to understand the lived experiences of workers' retirement preparation. The University of Ghana's Institutional Review Board approved the project. Confidentiality and anonymity were ensured.

\section{Research instruments}

Questionnaire

A questionnaire containing two sections was used in data collection. Section one was focused on the socio-demographic characteristics, namely age, educational level, and ethnicity. The second section explored issues of gendered retirement planning that were measured with a 5-point scale, ranging from "strongly agree" to "strongly disagree." Some of the questions were borrowed from Atchley (2000). Similarly, some of the response options were borrowed from Hershley and Mowen (2000) and Novak (2006). The questionnaire was created based on previous research, input from colleagues and also the study's research interests. After the definition of an initial pool of questionnaire items, qualified experts were made to review it, especially for grammatical corrections and accuracy. Before conducting a pilot of the questionnaire on the intended respondents, it was tested on a small sample of 30 individuals following the guidelines of Perneger et al. (2015). Afterward, a pilot test among the intended respondents for initial validation was undertaken. All participants completed the same questionnaire.

Collectively, the selected items were contextualized to fit this study and the Ghanaian scenario. The survey questionnaire instrument's reliability was ensured in diverse ways, namely, facilitation by clear instructions and wording of questions. The questionnaire contained standardized instructions namely "please tick where appropriate." Also, trait sources of error were minimized through interviewing respondents at their convenience. To attain this, interview appointments were scheduled. The survey data's validity was attained following Nardi's (2006) guidelines. The validity of the data was obtained from face-to-face interviews. Also, the survey sought an alternative source for confirmation through further in-depth interviews. The administration of the questionnaire took the form of face-to-face interviews, including self-administration. 


\section{Interviews}

The sample for the qualitative phase was selected from that used in the quantitative phase. Hence, statistical analysis from the quantitative phase was used to guide case selection from which additional information might be attained. At this phase, respondents who had participated in the quantitative phase also took part in follow up interviews. The participants were purposively selected on the basis of gender and sector of work. In consequence, the data was sorted into formal and informal sectors including gender in SPSS. As a result, 10 formal sector workers comprising 5 men and 5 women were purposively selected, as well as 10 informal sector workers, also evenly distributed by gender ( 5 males and females).

\section{Data Collection Process}

A questionnaire was used in data collection in the first phase. The administration of the questionnaire took the form of face-to-face interviews to prevent unreturned questionnaires. The study set out to investigate the hypothesis that there is an association between gender and retirement planning.

During the second phase, 20 participants who had participated in the initial phase also took part in follow up interviews with the purpose of obtaining an explanation for issues raised in the prior phase. In-depth interviews were used in the gathering of data. Prior to data collection, permission to tape record discussions and informed consent were obtained.

The interview guide and questionnaire were piloted to ensure accuracy in understanding, fluency and proper wording of questions. The face-to-face interviews were conducted in both English and Ghanaian languages, namely Ga, Ewe and Twi.

The interviews lasted approximately 45 minutes. Initially, the researcher reminded participants about the aims of the study and that the discussion would be used to suggest future directions. Each in-depth interview took the form of a semi-structured interview and was conducted individually in the participant's office or place of choice. The interviews were audio-taped.

\section{Data Analysis}

The quantitative data gathered were analyzed utilizing the Statistical Package for Social Sciences Software (SPSS) version 20.0, using frequencies, percentages and bivariate analysis - Pearson product moment coefficient tests were used in the study as the standard to assess the correlation between the degree of relatedness between gen- 


\section{Disaggregation of Gendered Differences in Retirement Planning in Urban Ghana}

der and retirement planning. The usage of a multi-stage sampling approach means that the results are statistically representative, thus, generalizability is permissible to the general population.

The in-depth interviews were preliminarily analyzed as they were being collected based on which modifications were made in the sampling strategy before the next series of interviews to ensure gaps were ascertained and rectified. This act preserved the multivocality and complexity of lived experiences while maintaining focus on the study's theme. The qualitative data analysis process was undertaken following Bryman's (2008) analysis strategies. A combination of the following analytic strategies was employed in this study. First, analytic induction, which was related to reaching general explanations, was used. Second, thematic analysis was undertaken in relation to the examination of theoretical themes of the research through studying particular cases. Finally, narrative analysis was used to search for new issues from the stories told by the research participants about their lives.

The analysis process was aided by the application of the framework method in which matrix-based comparisons were undertaken. This offered a detailed analysis of the data within a particular theme and provided a clearer and deeper understanding of key themes within the context of the study. Efficiency of the thematic analysis conducted was ensured following a variety of principles in the course of data processing. These include repetition in search of issues that are commonly repeated by interviewees, non-repetition in search of issues that were rarely mentioned by the interviewees; similarity and difference in a search of similar and different responses among interviewees on given themes such as tying (especially married) women's retirement plans to those of men; transitions in search for issues that link themes and sub-themes together. Theory linkage was also pursued, searching for connections to scientific concepts or theory for the outcome of research findings, such as the articulation of retirement aspirations as a fundamental goal in lieu of retirement planning. These were undertaken to ensure the pursuance of the relationship between categories and themes of data seeking to increase the understanding of the phenomenon.

Nvivo Software was used to facilitate text coding and retrieving coded texts, as well as interpret the data. The analytical process proposed by Bazeley and Jackson (2014) was followed, using five distinct steps. A project was created which comprised all the documents, coding data and related information that assisted in the process of data analysis as well as saving the NVivo project. The transcribed interview files were named respectively. Qualitative data files which entailed the preparation of docu- 
ments for import, following which the requisite documents that were intended to be analyzed were then imported. Additionally, nodes were engaged as a place in NVivo for references to code text.

A chunk of data were then coded. This included finding obvious themes as well as auto-coding. Subsequently, multiple codes were assigned to the same chunk of the texts including going through the same process. The codes formed a pattern. The passages of texts were compared and contrasted for ways in which they were similar and different. The emergent concepts entailed for example, perceived gender differences in retirement planning. The final step pertained to deepen the analysis and encompassed the following: the start of the analysis, going further with concepts, categories and themes including narratives and discourses. Memos were used to tell the story of the research by adding descriptions. The knowledge developed from the data was reported.

The outcomes of these activities were recorded in discussion memos. These strategies were integrated into the process of learning from the data. A thematic multi-case analysis was employed, the comparative focus of which was on individual cases including the preservation of their uniqueness. Miles and Huberman (1994) have succinctly expressed the goals of this type of analysis including generalizability.

Further counts of a theme within the unstructured text were used as a proxy indicator of the significance of that theme for qualitative analysis. The themes appeared as major findings and were used to create headings in the results section of the article. The interrelation between themes involved the use of narrative passages to convey the findings of the analysis. The themes were interconnected into a storyline. From these explorations, the researcher sought to understand how people construct meanings and actions, as preparations for understanding why people act the way they do (Charmaz, 2006). The final step entailed the selection, filtering and viewing of the predefined report for the study.

\section{RESULTS}

The study sample consisted of 213 males (48.2\%) and 229 females (51.8\%) aged between 18-59 years. Most of the respondents had some level of education. Overall, the highest educational level attained by a near majority of the respondents (46.4\%) was tertiary education. Thus, the sample is composed of a high proportion of university graduates. The sample also presented an even distribution between the formal $(\mathrm{n}=221,50 \%)$ and informal $(\mathrm{n}=221,50 \%)$ sectors. The marital status of the study 


\section{Disaggregation of Gendered Differences in Retirement Planning in Urban Ghana}

sample comprised married, co-habiting, separated, divorced, widowed as well as single participants. The majority of respondents from the formal sector were married (aproximately 72\%). More informal sector workers (28.5\%) were single whereas none were co-habiting or separated in the formal sector (Table 1 ).

\section{Table 1}

Respondent Demographics

\begin{tabular}{cccc}
\hline Variables & Characteristics & $\begin{array}{c}\text { Formal sector } \\
\text { Percentage (\%) }\end{array}$ & $\begin{array}{c}\text { Informal sector } \\
\text { Percentage (\%) }\end{array}$ \\
\hline Age & $18-29$ & 13.6 & 16.7 \\
& $30-39$ & 29.9 & 33.9 \\
Sex & $40-49$ & 34.4 & 21.7 \\
& $50-59$ & 22.2 & 27.6 \\
Education & Male & 51.6 & 48.3 \\
& Female & 48.5 & 51.4 \\
& No-formal education & 0.0 & 5.4 \\
Marital status & Pre-tertiary education & 17.5 & 82.5 \\
& Tertiary education & 89.3 & 10.7 \\
& Married & 71.9 & 52.0 \\
& Co-habiting & 0.0 & 4.9 \\
& Separated & 0.0 & 2.3 \\
Occupation & Divorced & 1.8 & 5.9 \\
& Widowed & 2.7 & 6.3 \\
& Single & 23.5 & 28.5 \\
& Office work & 30.5 & - \\
& Teaching & 19.5 & - \\
& Trading & - & 24.5 \\
& Driving & - & 12.4 \\
& Artisanry & -7 & 12.7 \\
\hline
\end{tabular}

Source: Field data, 2016

The study participants differed in professional experiences and in personal characteristics, but all were identified as individuals who expressed divergent views on the theme of the study.

The occupational categorization of the study respondents encompassed office work (30.5\%), teaching (19.5\%), trading (24.5\%), driving (12.4\%) and artisans (12.7\%). Against this backdrop, office work and teaching categories constitute the predominant formal sector work whilst trading, driving and artisans denote informal sector work (Table 1). 


\section{Workers' Retirement Aspirations and Plans}

Retirement aspiration and/or expectations encompass things needed to plan for in aid of financial security (13.5\%) intimated by women vis-à-vis social networking (Figure 1). It is worth noting that these aspirations and/or expectations confirm Atchley's theoretical statement that retirement goals precede retirement planning as an idle prerequisite.

\section{Figure 1}

The Most Important Things to Consider when Planning for Retirement: Gender Differences in Retirement Needs

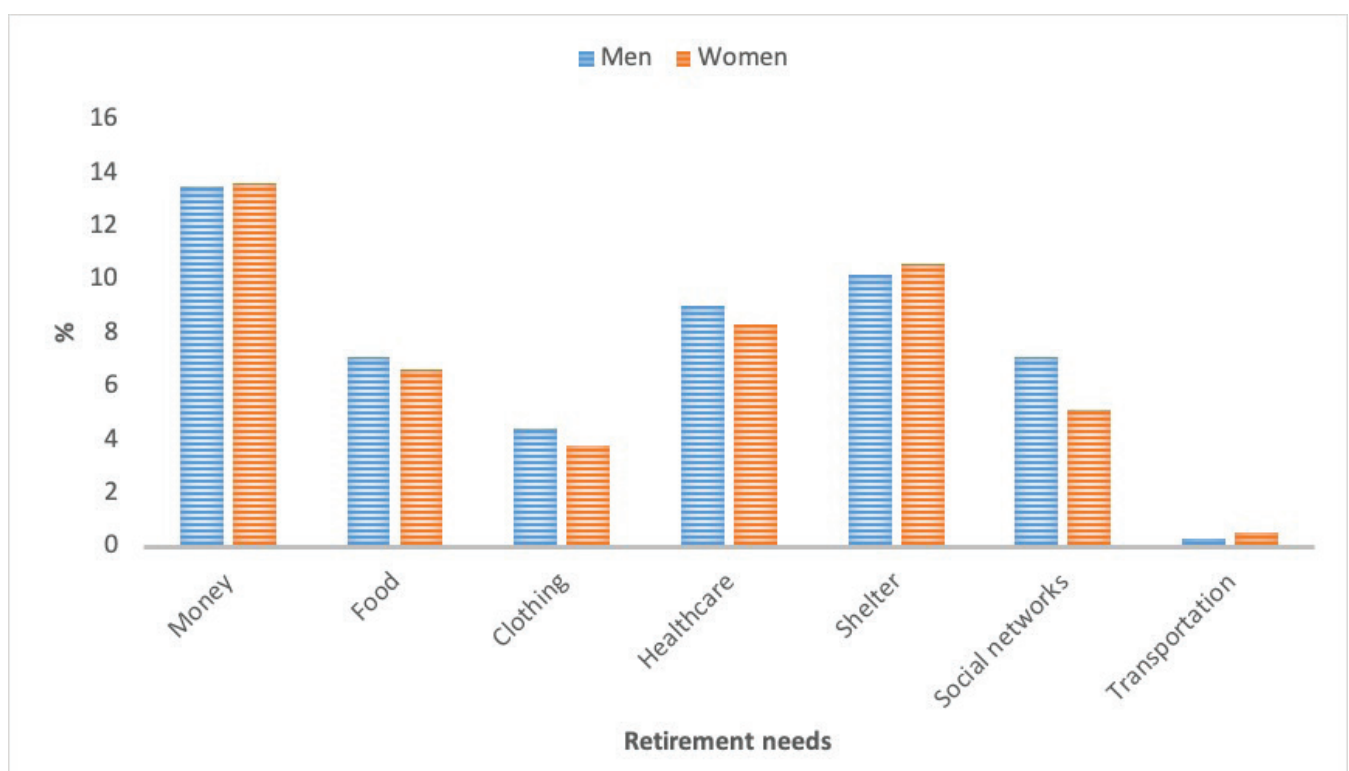

Source: Field data, 2016.

\section{Expected Sources of Finance for Utilization during Retirement}

The need for financial security in old age cannot be overemphasized. Thus, the results show that more women workers look forward to dependence on spouse's pension income $(11.1 \%)$ whereas women in general $(0.7 \%)$ largely hope to rely on support from the church (Figure 2). From the statistics, children as a source of retirement finance appears to be more emphasized for women than men with significance for social insurance dynamism, in terms of which this finding corroborates Caldwell's theoretical 


\section{Disaggregation of Gendered Differences in Retirement Planning in Urban Ghana}

stipulation inasmuch as it states that workers plan for child care with social insurance in old age as the anticipated outcome. The women's views from the interview data emphasize the existence of different motives and desires towards retirement and the related planning. Thus, a man from the formal sector asserted that "there are different individuals with their mind sets, different aspirations and expectations".

All the constituents on Figure 2 may collectively yield financial security for the individual workers when instituted. Also worthy of note is that workers aspired to have both financial and non-financial (or social resources) on which to depend during retirement.

\section{Figure 2}

Expected Sources of Financial Income for Retirement

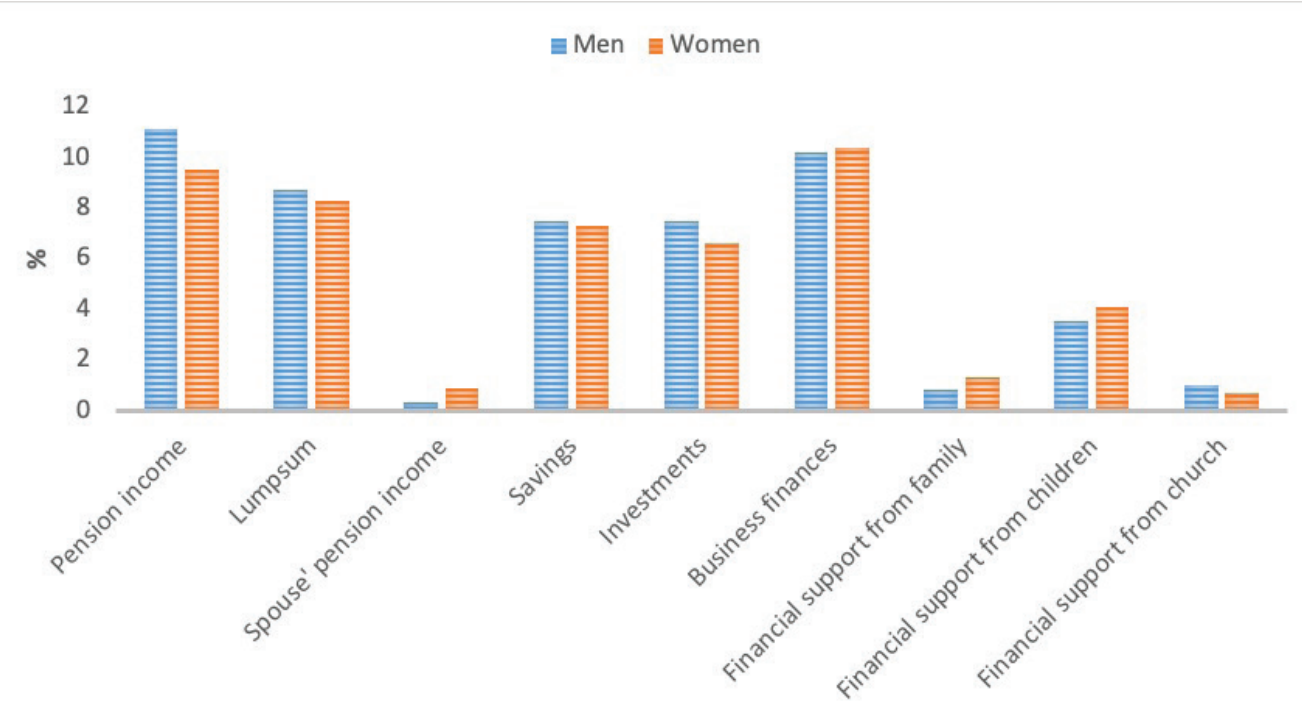

Financial expectations for retirement

Source: Field data, 2016.

The respondents, however, expected that such savings, when accumulated, should be able to cater for their needs for a period of five years after retirement until death. The notion of 'till death' may span from immediately after retiring from active work or several years thereafter, albeit shrouded in perceptions of longevity. Noteworthy is that these retirement aspirations and/or expectations influenced the institution of workers' plan portfolios. In addition, these findings corroborate the theoretical views of Atchley (2000). 


\section{Table 2}

Retirement plans instituted

\begin{tabular}{|c|c|c|}
\hline Measures & Men (\%) & Women (\%) \\
\hline Retirement savings & 28.6 & 71.4 \\
\hline Life insurance & 47.6 & 52.4 \\
\hline Fixed deposits & 66.7 & 33.3 \\
\hline Susu & 0 & 100.0 \\
\hline Pension contribution & 54.2 & 45.8 \\
\hline Monitor investments & 48.1 & 51.9 \\
\hline Family planning & 40 & 60 \\
\hline Join association(s) & 47.4 & 52.6 \\
\hline Investment in children's education & 33.3 & 67.3 \\
\hline House acquisition & 47.5 & 52.5 \\
\hline Land acquisition & 43.8 & 56.2 \\
\hline Provident fund & 66.7 & 33.3 \\
\hline Mutual fund & 94.5 & 5.5 \\
\hline Health plan & 70.0 & 30.0 \\
\hline Dieting \& fitness program & 57.8 & 42.2 \\
\hline Periodic health checks & 42.9 & 57.1 \\
\hline T-bills & 42.9 & 57.7 \\
\hline Figure out retirement aspirations & 51.8 & 48.2 \\
\hline Explore partial retirement options & 50.0 & 50.0 \\
\hline Develop interests, friendships, \& skills outside work & 51.2 & 48.8 \\
\hline Shares & 66.7 & 33.3 \\
\hline Stocks & 61.2 & 38.8 \\
\hline Epack & 0.0 & 100.0 \\
\hline Mfund & 0.0 & 100.0 \\
\hline Funeral policy & 0.0 & 100.0 \\
\hline Diversification of income sources & 40.6 & 59.4 \\
\hline Expand business & 0.0 & 100.0 \\
\hline Diversification of portfolios & 42.9 & 54.1 \\
\hline Social relationship building & 47.1 & 52.9 \\
\hline Credit union membership & 28.6 & 71.4 \\
\hline
\end{tabular}

Source: Field data, 2016.

More female workers predominated in instituting susu, savings, pension contributions including the monitoring of retirement investments, land acquisition, periodic health checks (Table 2). The formal sector also dominated in family planning (60\%), provident fund, T-bills, shares, stocks, relationship formation among others.

Both genders however undertook the joining of associations. This may be an indication of seriousness at planning and an awakening to the realization of an impending 


\section{Disaggregation of Gendered Differences in Retirement Planning in Urban Ghana}

transition. The retirement plans instituted by the study sample show that more men (61.2\%) invested in stocks and women (51.4\%) undertook portfolio diversification.

These measures can further be categorized into planning strategies (e.g. monitoring of investments, family planning, diversification of income sources, diversification of portfolios); savings and/or investments (e.g. retirement savings, life insurance, fixed deposits, susu, pension contribution, investment in children's education, house acquisition, land acquisition, provident fund, mutual fund, T-bills, will, shares, stocks, Epack, Mfund, funeral policy); healthcare (e.g. health plan, dieting, health checks); and social relationships (e.g. join association, investment in the education of children and/or wards). The data from interviews indicates that participants who articulated the expected sources of finance for retirement utilization, four of them documented the following:

Putting all your retirement investments in one basket is suicidal. Do you remember the pyram scam? Hmmm, so the ideal way is to spread them. Hence, my resort to plan diversification (Formal sector man).

As for me, I have not collected the accrued money for five years now... because I want it to remain there as my pension money (Formal sector woman).

I have enrolled in the premier health insurance plan for purposes of my old age (Informal sector woman).

The association ensures access to information related to insurance, savings, sika plan and many more.... It also makes contributions to support members in times of ill-health, outdooring, bereavement as well (Informal sector woman).

Further, the survey data was subjected to Pearson Chi-square statistics and Cramer's $\mathrm{V}$ test to assess the association between gender and retirement planning (Table 3). The Cramer's V=0.706 indicates a strong association between the two variables. 


\section{Table 3}

Chi-Square Statistics for Gender and Retirement Planning

\begin{tabular}{lccc}
\hline \multicolumn{1}{c}{ Tests } & Value & $\begin{array}{c}\text { Degree } \\
\text { of freedom }\end{array}$ & $\begin{array}{c}\text { Asymp. Sig. } \\
\text { (2-sided) }\end{array}$ \\
\hline Pearson Chi-Square & $499.222 \mathrm{a}$ & 10 & .000 \\
Cramer's V & 0.706 & 10 & .000 \\
N of Valid Cases & 442 & & \\
\hline
\end{tabular}

Source: Field data, 2016.

\section{Gender Differences in Retirement Planning}

Figure 3 shows the participants' perception of gender differences in retirement planning. In our sample, $10.2 \%$ of women participants perceive "a lot" of differences between sexes (10.2\%), whereas only $7.2 \%$ of the men identify differences of this magnitude. However, a large number of women also tend to affirm that no differences exist at all in retirement planning (31.2\%), but this percentage is somewhat lower in men (27.4\%). In both sexes, the perception that no gender differences exist predominates.

\section{Figure 3}

Depiction of Gender Differences in Planning for Retirement

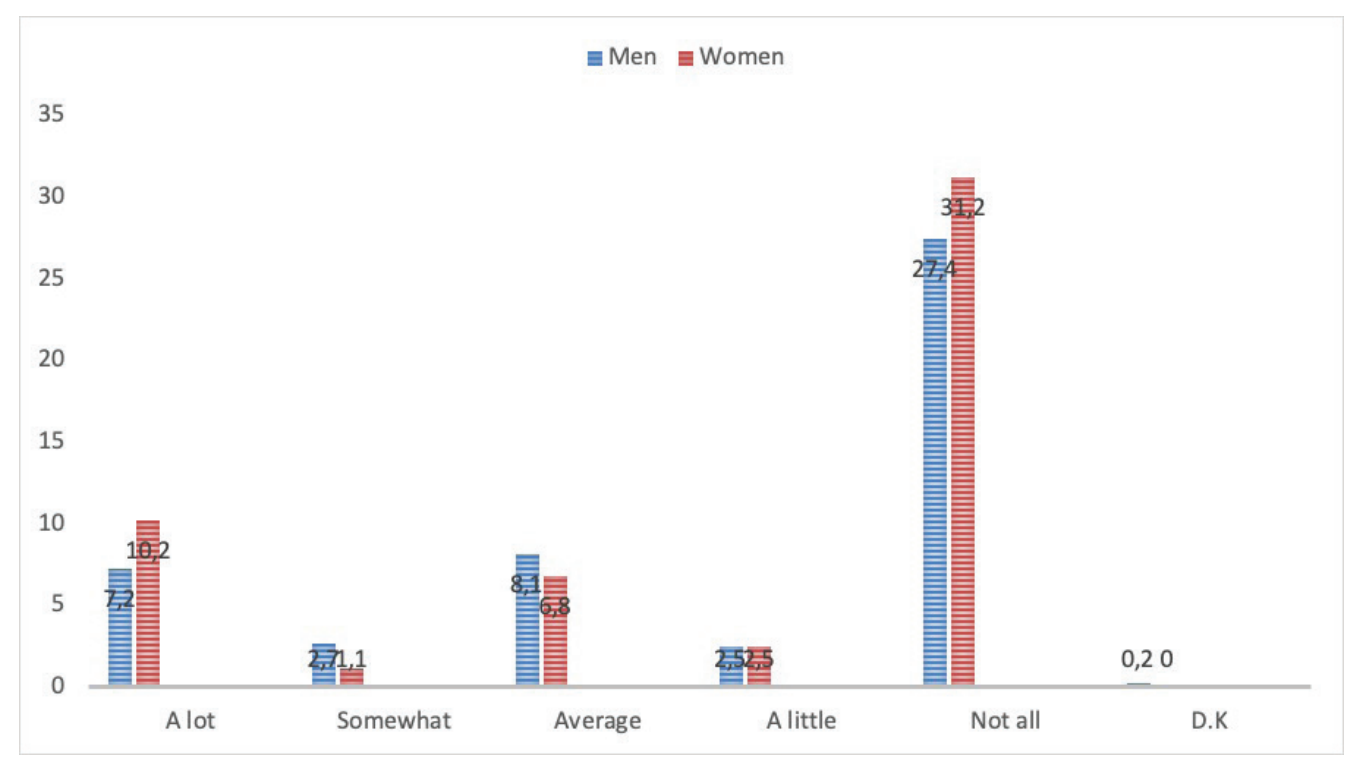

Source: Field data, 2017. 


\section{Disaggregation of Gendered Differences in Retirement Planning in Urban Ghana}

Interviews allowed for a better understanding of the gender differences that some respondents identify. For example, "it depends on what one is interested in, but women manage funds better than men do except for their impulsive buying" (Informal sector man). This perspective from a male participant highlights the attribution of two qualities to women: better management funding associated with impulsive purchasing. Another male participant, considered that retirement planning is not a major concern for women, because they can rely/depend on their husbands: "on the average women don't have challenges looking up to the future because the better half is there" (Formal sector man). Another male respondent considered that this perceived laissez-faire regarding retirement planning on the part of women derives from their focus on domestic chores: "they do so in view of the fact that they take care of the home" (Formal sector man). Quite apart from the fact that women have been depicted as better fund managers, "somehow, some women have more money than men and vice versa" (Informal sector man).

The voices may suggest that retirement planning is much easier for married or cohabiting women than their unmarried/non-cohabiting counterparts, although there could be exceptions to this notion. Further still, no matter the level of support received during the process of retirement planning, including the availability of funds, all planners (women included) are impacted by impediments of one form or the other such as capital market volatility, inflation and a host of others. It suggests that when it comes to retirement planning, married women particularly exert less financial efforts and resources with more emanating from their spouses notwithstanding the fact that women may be better fund managers. Yet, some women do not depend financially on their spouses in lieu of retirement planning. Theoretically, this finding is consistent with Bandura's (1977) intimation in terms of social learning acquired through the process of socialization in relation to perceiving men as family heads and more aggressive. This also has implications for the notion that women's retirement plans are tied to those of men.

\section{Do women prepare better than men?}

The notion that women prepare better than men was not left out and was documented by three participants. For instance, an informal sector male worker stated that "women prepare more adequately than men do because they suffer most when the going gets tough, especially those women who work". This includes the fact that "women prepare more in investing in their families whilst men concentrate on properties such as houses, etc" (Formal sector man). This is reminiscent of perhaps low income levels and the consequent investment of financially less intensive retirement assets as articulated below. 
Another woman from the informal sector reported that "both men and women need to plan for retirement. It is very important. But women need to do more than men because women most often do not have social security". In furtherance to this, there is the issue of women living longer comparatively than men and therefore the need to be forearmed against that. Significant about retirement planning is the facilitation by income which is comparatively low among women. For example, it was observed that "in the case of women the issue is low income flow in some cases, whereas there is more financial flow in the case of their male counterparts" (Informal sector woman).

\section{Women's Retirement Preparations are Patterned around Men's}

Divergent views were also expressed on whether a woman's retirement preparations are tied to those of a man in the Ghanaian society from a marital status point of view. A cross tabulation between a woman's preparation for retirement is tied to that of a man and marital status showed that married respondents tend to strongly agree with this assertion, whereas only $1.8 \%$ singles do so. Singles present a more marked tendecy for agreement, neutrality or even disagreement, but married participants also espouse these perspectives.

\section{Figure 4}

A Woman's Retirement Preparations Are Tied to Men's

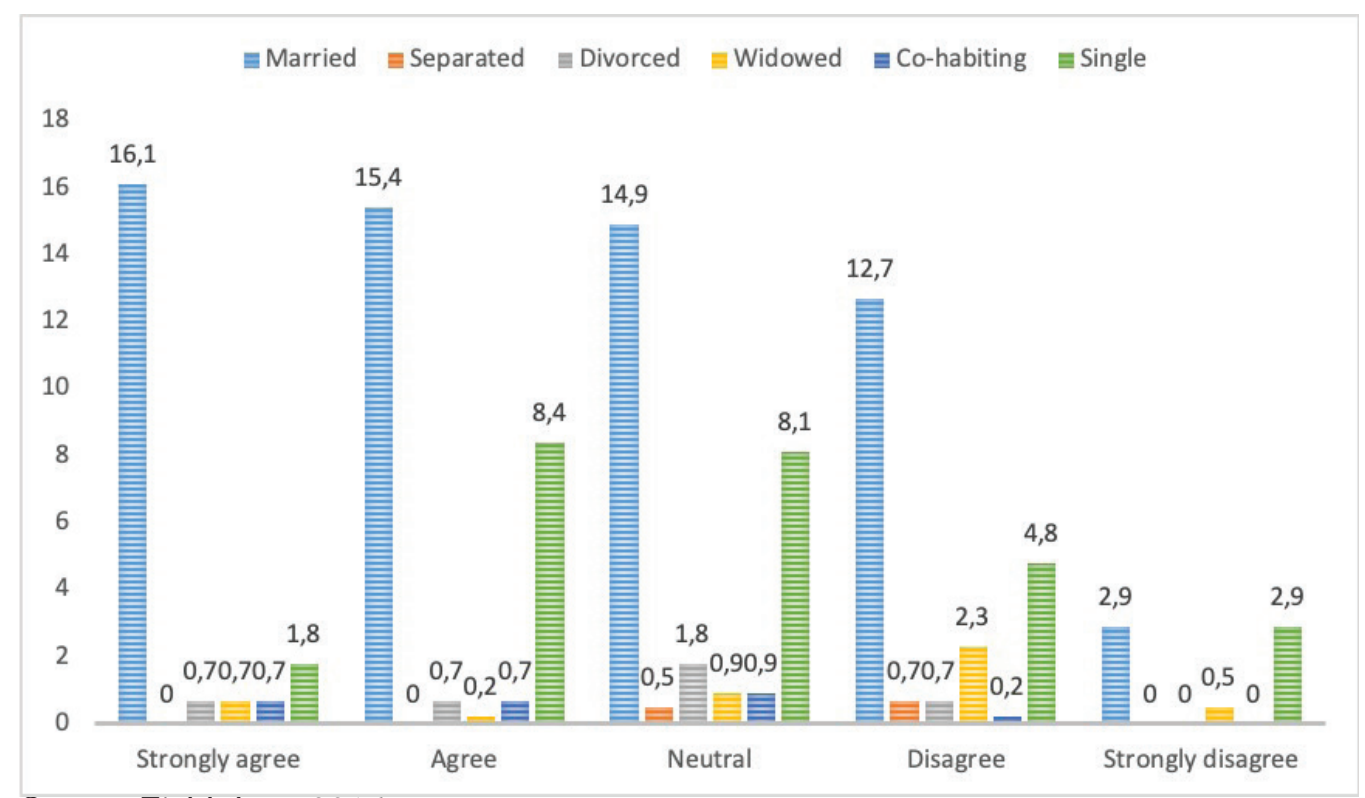

Source: Field data, 2016. 


\section{Disaggregation of Gendered Differences in Retirement Planning in Urban Ghana}

Using the qualitative data, perceptions in relation to the tying of women's retirement plans around those of men has been disaggregated along the pathways of interdependent gender dynamics; independent dynamics in retirement planning and attitudinal patterns as follows.

\section{Interdependent Gender Dynamics in Retirement Planning}

From the interview data, three participants who agreed to the assertion that, a woman's retirement preparations are tied to that of a man documented the following facts:

A man is always the head of the family (Informal sector man).

From observation, most female retirees always want to be closer to their partners at houses and do whatever activity thereof (Informal sector man).

Since the man is generally considered the head of the family and is likely to focus on acquiring physical assets e.g. homes and women tend to support in such areas (Formal sector woman).

Essentially, these statements are reflective of interdependent patterns. It is also a depiction of Bandura's (1977) stipulation.

\section{Independent/separate Gender Dynamics in Retirement Planning}

The fact that retirement planning can be undertaken by both men and women independently was further echoed. This point is backed by the quote that "the woman can do hers separately" (Informal sector man). In support of the above point, disagreeing views from twelve out of 20 participants that has shown the extent of independence between men and women, even in such matters as retirement planning, including different levels of societal responsibilities. As a result, the following observations have been made:

They are two independent people as well as contributors (Informal sector woman).

Different responsibility levels considering our culture (Formal sector woman).

A woman's needs and reasons for retirement preparation are totally different from those of a man (Formal sector woman).

Because when you are not there, his family will say it is all his (Informal sector woman). 
Beijing conspiracy' is revoked by the notion that 'whatever a man can do, a woman can do same and even better (Informal sector woman).

I am coming from the premise of the fact that I was an individual long before I got married and that fact still remains. And so I need to take care of my own needs including the retirement related ones (Formal sector woman).

Marriage is a unifier but not a terminator of individual destinies and the associated individual responsibilities (Informal sector woman).

Men are contemporarily self-seeking and self-serving and women need to watch out more for themselves when it comes to their retirement matters and needs (Formal sector woman).

If in my old age after I have retired, my husband dies, and family contestations ensue and if I have not planned for my own sake, where do I go from there? As women, we need to wise up on these issues because sometimes the men die and their families come to take up everything, leaving their widows poor in the real sense of the word. It is just like milking the rhino (Informal sector woman).

As spouses, we do different jobs and so there is the need to plan separately (Formal sector man).

In fact, men and women planning independently or separately only leads to advantageous resource mobilization and accumulation for a better old age (Formal sector man).

The above voices have weaved notions of marriage dynamics extensively into the discussion of retirement planning including family related maltreatments unjustly meted out to women, especially on the demise of their spouses. This attenuates the call for independent planning for retirement despite linkages to marital ties, while highlighting retirement planning related individualisation. These views also extend the argument made based on the quantitative data presented in Figure 5 above.

Therefore, not all women's preparations may be tied to that of men. For example, another woman participant argued that 'a woman's retirement preparations are tied to those of a man in society mostly for housewives but not for non-house wives. Robertson (1984) intimated that gender duality discourse as earlier stated brings to the fore a gender division of labor where economic responsibility of both men and 


\section{Disaggregation of Gendered Differences in Retirement Planning in Urban Ghana}

women is seen as separate but complementary and where what is expected of each person is well defined.

\section{Attitudinal Patterns in Gender Dynamics in Retirement Planning}

The views of men in the in-depth interview data generally demonstrates attitudinal patterns that compared to women, men are compelled to plan, which implies that women compared to their male counterparts are more serious in life. Three participants refered that: "men only plan when the company facilitates that" (Formal sector man). However, this assertion may not be a given, as the contexts that induce such grounds may differ across locations, cultures and epochs in time among others. Additionally, it was alleged that "women are more serious about things whereas men are not" (Informal sector man). Further, it was reported that "women invest in savings, bonds, etc, men invest in T-bills, savings, bonds, etc”. (Formal sector man).

\section{DISCUSSION}

The findings show that a great deal of difference exists between men and women in terms of how they prepare towards retirement because the latter do so in view of the cultural expectation that they should take care of the home. The findings indicate that by virtue of retirement aspirations, female workers expected to ascertain social networking compared to their male counterparts who envisaged financial security. These retirement aspirations and/or expectations by and large precipitated the institution of workers' plan portfolios. Predominantly, more women instituted susu, savings, pension contributions including the monitoring of retirement investments, land acquisition, periodic health checks. Both gender however undertook the joining of associations. It is worth noting that these aspirations and/or expectations confirm Atchley's theoretical statement that retirement planning should at least in most cases precede the mobilization of retirement life oriented resources.

The workers opined that a woman's retirement preparations are tied to those of a man in the Ghanaian society, particularly the married ones, mostly the housewives but not for non-housewives. The adduced reasons encompass the perspective that men are the heads of their households and the consideration that women desire to be close to their partners. Yet, not all women's preparations may be tied to those of

men. On the other hand, men often plan for retirement with the support of their 
female partners. More married respondents strongly agree with the assertion that women's retirement plans are tied to those of men. This study shows that there is a strong association or relationship (Cramer's $V$ test value of 0.706 ) between gender and retirement planning. This is indicative of the fact that women suffer marginalization (Dzorgbo \& Gyan, 2014) in financial terms, with implication for negative name calling, stereotyping and stigmatization in all facets of life including gendered retirement planning dimensions.

The disagreeing views show the extent of independence between men and women in matters of retirement planning pertaining to the fact that they are two independent people as well as contributors with different responsibility levels including the fact that women's needs and reasons for retirement preparation are entirely different from those of men, not to mention consideration of extended family interferences. This suggests that couples are increasingly undergoing two retirements. Penultimately, what prompts women to plan differs from what motivate men. This provides a reinforcement of the importance of considering gender when seeking to understand the variables predictive of planning tendencies.

Retirement planning is facilitated by incomes, which, men are more endowed with than women. These differences in income might have implications for women's extent of planning, including the propensity for risk aversion. Thus, whereas men focus on physical assets, women concentrate on social relationships or networking pathways. The latter has implications for financial risk taking and the associated risk aversion.

The findings also show gender dynamics in interdependent; independent/separate and attitudinal patterns situated within cultural underpinnings. On the one hand, planning interdependently for retirement may highlight attributes of corporate planning for a singular course albeit post-retirement life. On the other hand, planning separately for the same course only increases the urgency of planning for life in general and retirement in particular. After all, life and its extricate trajectory is unpredictable and therefore must be guarded against to prevent unpleasant exigencies, such as family related maltreatments unjustly meted out to women, especially on the demise of their spouses. This brings to the fore the importance of retirement planning related individualisation. Further, the role of attitudinal patterns cannot be underestimated. In essence, culture then underpins and/or influences the gendered dimension of retirement planning. In addition, men and women experience retirement differently, so does their experience of adjustment to retirement. The difference 


\section{Disaggregation of Gendered Differences in Retirement Planning in Urban Ghana}

may also lie in their respective retirement aspirations, where to live after retirement, time spent planning, the duration thereof, income levels, as well as the focus of the plan. Existing studies (e.g., Fisher 2010; Jacobs-Lawson, Hershey \& Neukam, 2004) have reported that most gender differences in planning are due to the fact that women have lower incomes compared to men. The variables that "prompt women to plan differ from those that motivate men, thus reinforcing the importance of considering gender when seeking to understand the variables predictive of planning tendencies" (Jacobs-Lawson et al., 2004, p. 66).

Looney et al. (2007) assert that women appear to be conservative in their investment ventures because of "the tendency to sacrifice higher returns in favor of safety to hurt the retirement portfolios of female investors the most" (p. 1). Men and women define and experience retirement differently (Robin et al., 2011) and therefore plan for it differently. Besides, men spend more time planning than women do (BMO Wealth Institute, n.d). Similarly, Jacobs-Lawson et al. (2004) document that there are gender differences in the time spent thinking about retirement and planning towards it. Significantly, the paramountcy of women's financial decision making responsibilities are because of their longer life span compared to men (BMO Wealth Institute, n.d; Fisher, 2010; Morrin et al., 2011). Further, BMO Wealth Institute argues that historically men's identities have been very closely tied to their work, which is often not replaced on the event of retirement. There is evidence to suggest that a woman's life experiences prepare her better for retirement when "the job experience no longer takes centre stage" (n.d. p.7).

A number of studies have found that men think more about their future life in retirement (Jacobs-Lawson et al., 2004) and their future finances and are more likely to discuss retirement with friends, relatives, and co-workers (Moen et al., 2000). But the differences were statistically significant, but relatively small (Jacobs-Lawson et al. 2004; Moen et al., 2000), or no gender differences were found (Schellenberg et al., 2005). However, other research has found no gender differences in financial preparedness (Hershey \& Mowen, 2000). Inconsistencies and contradictory findings in the current literature suggest that women are less disadvantaged in terms of retirement planning currently than in previous epochs.

The notion of tying women's retirement plans around those of men may also be analyzed as follows. Developmental processes always take place in the context of ongoing social relations, including developmental shifts that occur with retirement. Individuals frequently decide to retire on the basis of changes in others' health and/or 
retirement exits or plans. Furthermore, the retirement experience is played out in a network of shifting social relations. It is crucial to consider the work or retirement statuses of both spouses, given that each spouse's retirement transition represents an important life event for the couple, requiring adjustment on the part of both spouses. Research on retirement adjustment suggests that marriage and family relationships serve as social-relational resources in retirement adjustment (Mutran et al., 1997). Strong emotional support from a spouse may well help individuals overcome stressful life events, thereby sustaining their psychological well-being.

\section{THE RETIREMENT PLANNING GLASS CEILING}

Tzannatos (1999 cited in Darkwah, 2014, p. 137) opines that inequalities hurt and that they hurt both women and men. This article provides a sociological analysis of some of the challenges or problems men and women encounter from structure and agency perspectives. These are grouped under (1) economic and (2) socio-cultural factors.

Economically, the fact that financial resource is the oil that greases the retirement planning machinery cannot be underestimated. Successful retirement planning implies that the planner must have some amount of money and the requisite planning information. Yet, the literature on gender issues posits that generally women have inadequate financial resources (Dzorgbo \& Gyan, 2014) with respect to life in general and towards retirement planning in particular. Thus, to be successful, women have to be mostly dependent on their spouses for financial support.

Women's retirement planning to a large extent is shaped by cultural considerations or factors. "Traditionally, women and men are usually socialized to assume different roles in society" (Dzorgbo \& Gyan, 2014, p.131). In performing such roles, women move in and out of work to have babies or take care of their ailing spouses, parents, grandparents and significant others. Is is not uncommon that married women have to quit their jobs upon childbirth (Darkwah, 2014). Collectively, these issues have implications for their financial status, as retirement planning in its entirety relies on funds, a resource that women tend to lack in abundance. These structural challenges encountered by women have tremendous repercussions for their preparedness towards retirement in its adequate measure. 


\section{Disaggregation of Gendered Differences in Retirement Planning in Urban Ghana}

\section{CONCLUSION AND RECOMMENDATIONS}

The study espouses the fact that gender is strongly related to retirement planning. Gendered retirement planning espouses retirement planning disaggregated along gender lines, including strengths dissipated financially albeit quasi-financially in favor of men and women. Gendered retirement planning dynamics in interdependent independent/separate and attitudinal patterns are situated within cultural underpinnings. Culture underscores and/or influences the gendered dimension of retirement planning. However, women's retirement planning process is by and large delimited by low income status including risk aversion and cultural connotations. Retirement and retirement planning is now of greater concern for women. However, women are less likely than men to actively plan for retirement, women appear to have a greater need to intitute more plans than men, and what prompts women to plan differs from what motivates men, inasmuch as married women and their co-habiting counterparts' mobilized retirement resources and/or plans are tied to those of their men.

Based on the findings of this study, the following recommendations are proposed. First, women's increasing representation in the workforce requires a reexamination of their retirement plans and the factors that enable them in Ghana. Second, the extent to which women are disadvantaged in terms of their retirement planning and the factors that may affect retirement plans needs to be assessed. Future promotional initiatives should be aimed at these groups to assist their financial preparations for the future. Third, the essence of considering gender when seeking to understand the variables predictive of planning tendencies is recommended. Further research on gender and retirement planning should explore women's general orientation, interests and priorities, including how they are mobilizing retirement resources strategically.

\section{REFERENCES}

Aboderin, I. (2006). Intergenerational support and old age in Africa. New Brunswick, New Jersey: Transactions.

Addo, E. O. (2017). The impact of manufacturing industries in Ghana's economy. Internatioal Journal of Research Studies in Management, 6(1), 73-94. 
Agblobi, A. D. (2011). Pensions: The new instrument perspective for retirement planning. Accra: Mork Impressions.

Angel, J. L., Jimenez, M. A., \& Angel, R. J. (2007). The economic consequences of widowhood for older minority women. The Gerontologist, 47, 224-234. https:// doi.org/10.1093/geront/47.2.224

Atchley, R. C. (1982). Retirement: Leaving the world of work. The Annals of American Academy of Political and Social Science. https://doi. org/10.1177/0002716282464001011

Atchley, R. C. (1999). Continuity and adaptation in aging: Creating positive experiences. John Hopkins: Johns Hopkins University Press.

Atchley, R. C. (2000). Social forces and aging (9th ed). Belmont, CA: Wadsworth.

Atchley, R. C., \& Barusch, A. S. (2004). Social forces and aging (10 ${ }^{\text {th }}$ ed.). Wadsworth Press.

Baah_Boateng, W. (2007). Measuring the extent of gender segregation in the labour market: evidence from Ghana. GIMPA Journal of Leadership, Management and Administration, 5(1), 57-81.

Bandura, A. (1977). Self-efficacy: Toward a unifying theory of behavioral change. Psychological Review, 84, 191-215.

Barrow, George. M. (1986). Ageing, the Individual and Society (3rd ed.). New York: West Publishing for Company.

Bazeley, P., \& Jackson, K. (2014). Qualitative data analysis with Nvivo, (2 ${ }^{\text {nd }}$ ed.). Sage.

Berggren, J., \& Gonzalez, R. (2010). Gender difference in financial decision-making - A quantitative study of risk aversion and overconfidence between the genders. Retrieved from http://www.diva-portal.org/smash/get/diva2:324378/FULLTEXT01.pdf

BMO Wealth Institute (n.d). Divergent paths to retirement: How men and women plan differently. Retrieved February 20, 2017 from http://bmo.com/wealthinstitute. 


\section{Disaggregation of Gendered Differences in Retirement Planning in Urban Ghana}

Bryman, A. (2008). Social research methods (3rd ed.). Oxford: Oxford University Press.

Caldwell, J. C. (1976). Toward a restatement of demographic transition theory". Population and Development Review, 2(3/4), 321-366.

Caldwell, J. C. (2005). On net intergenerational wealth flows: An update. Population and Development Review, 31(4), 721-740.

Charmaz, K. (2006). Constructing grounded theory. Thousand Oaks: Sage.

CIA World Factbook (2019). GDP-composition by sector. Retrieved from http://www. indexmundi.com

Clare, L. (2004). Awareness in early-stage Alzheimer's disease: A review of methods and evidence. British Journal of Clinical Psychology, 43(2), 177-196. https://doi. org/10.1348/014466504323088042

Correll, S.J., Benard, S. \& Paik, I. (2007). Getting a job: Is there a motherhood penalty? American Journal of Sociology, 112(5), 1297-1339.

Cunningham, W. (2007). Minimum wages and social policy: Lessons from developing countries. Retrived from https://openknowledge.worldbank.org/ handle/10986/6760

Darkwah, A. (2014). Structural gendered inequalities in the Ghanaian economy. In D.B.S. Dzorgbo and S. Tonah (Eds.), Sociology and development issues in Ghana (pp. 137-151). Woeli Publishing Services.

De-Graft Aikins, A., Kushitor, M., Sanuade, O., Dakey, S., Dovie, D. A., \& KwabenaAdade, J. (2016). Research on Aging in Ghana from the 1950s to 2016: A Bibliography and Commentary. Ghana Studies Journal, 19, 173-189.

Dovie, D. A. (2017). Preparations of Ghanaian formal and informal sector workers towards retirement. [Unpublished Doctoral Thesis] University of Ghana, Accra.

Dovie, D. A. (2018a). Retirement planning: A mechanism for combating age reduction. Centre for Ageing Studies Newsletter, 1(2), 4-5. 
Dovie, D.A. (2018b). Systematic preparation process and resource mobilisation towards post-retirement life in urban Ghana: An Exploration. Ghana Social Science Journal, 15(1), 64-96.

Dovie, D. A. (2019a). Utilizing retirement planning as leverage for age reduction among workers. In $€$. Tomczyk \& A. Klimczuk (Eds.), Between successful and unsuccessful ageing: Selected aspects and contexts (pp. 23-57). Kraków: Uniwersytet Pedagogiczny wKrakowie. http://doi.org/10.24917/9788395373718.2

Dovie, D. A. (2019b). The influence of MIPAA in formal support infrastructure development for the Ghanaian elderly. International Journal of Ageing in Developing Countries, 3, 47-59.

Dovie, D. A. (2019c). Leveraging social media induced visual culture for body image enhancement: The case of socialization in a contemporary society. Vista - Visual Culture Journal, 4, 117-152. Special Issue on Visual, Digital and Media Culture: Images among Generations.

Dovie, D. A. (2019d). Exploring the nexus between family size planning and retirement planning in Ghana. Interações: Sociedade E As Novas Modernidades, 37, 183-216. http://doi.org/10.31211/interacoes.n37.2019.a8

Dovie, D. A. (2020). Articulation of the shallow inclusion and deep exclusion of older adults from the Ghanaian policy terrain. Journal of Public Policy Studies (in press).

Duflo, E., \& Saez, E. (2003). The role of information and social interactions in retirement plan Decisions: Evidence from a randomised experiment. Quarterly Journal of Economics, 118, 815-842.

Dzorgbo, D. B. S., \& Gyan, S. E. (2014). Democratic governance and women representation in Ghana: A critical evaluation of the progress. In D.B.S. Dzorgbo and S. Tonah (Eds.), Sociology and Development Issues in Ghana (pp. 115-136). Woeli Publishing Services.

Fennell, M.L., Barchas, P.R., Cohen, E. G., McMahon, A. M., \& Hildebrand, P. (1978). An alternative perspective on sex differences in organizational settings: The process of legitimation. Sex Roles, 4, 589-604. https://doi.org/10.1007/ BF00287203 


\section{Disaggregation of Gendered Differences in Retirement Planning in Urban Ghana}

Fisher, P. J. (2010). Gender differences in personal saving behavior. Retrieved from https://afcpe.org/assets/pdf/volume_21_issue_1/pattiejfisher.pdf

Foster, L., \& Walker, A. (2014). Active and successful aging: A European policy perspective. The Gerontologist 55, 83-90.

Fox, J. J., Bartholomae, S., \& Gutter, M. S. (2000). What do we know about fnancial socialization? Consumer Interests Annual, 46, 217.

Greenspan Commission. (1983). Report of the National Commission on Social Security Reform. https://www.ssa.gov/history/reports/gspan.html.

GSS (2014). 2010 Population and Housing Census. Retrieved from http://www. statsghana.gov.gh/docfiles/2010phc/Census2010_Summary_report_of_final_ results.pdf

Hatch, L. R. (1990). Gender and work at midlife and beyond. Generations, 14, 48-52.

Hershey D. A., Jacobs-Lawson J. M., McArdle J. J., \& Hamagami F. (2007). Psychological foundations of financial planning for retirement. J. Adult Dev. 14, 26-36. 10.1007/s10804-007-9028-1

Hershey, D. A., \& Mowen, J. C. (2000). Psychological determinants of financial preparedness for retirement. Gerontologist, 40 (6), 687-697.

Holzmann, R., \& Stiglitz, J. (2001). Introduction. In R. Holzmann, J. Stiglitz, L. Fox, E. James, and P. Orszag (Eds.), Toward sustainable pension systems in the $21^{\text {st }}$ century: New ideas about old age security (pp. 1-16). Washington D.C.: The World Bank.

Jacobs-Lawson, J. M., Hershey, D. A., \& Neukam, M. S. (2004). Gender differences in factors that influence time spent planning for retirement. Journal for Women and Ageing, 16(3\&4), 55-69.

Kim, J. E., \& Moen, P. (2002). Retirement transitions, gender and psychological wellbeing: A life course, ecological model". Journal of Gerontology: Psychological Sciences, $57 \mathrm{~B}(3), 212-222$.

Looney, C. A., Poston, R. S., \& Akhulut, A. Y. (2007). Advice ability and gender differences in risky decision making: A study of online retirement planning. Proceedings of the $40^{\text {th }}$ Hawaii conference on system sciences. 
McNeal, U. (1987). Children as consumers: Insights and implications. Lexington, MA: Lexington Books.

Miles, M. B., \& Huberman, A.M. (1994). Qualitative data analysis: An expanded sourcebook. Thousand Oaks, CA: Sage.

Moen, P., Fields, V., Quick, H., \& Hofmeister, H. (2000). A life course approach to retirement and social integration. In K. Pillemer, P. Moen, E. Wethington, \& N. Glasgow (Eds.), Social integration in the second half of life (pp. 75-107). Baltimore: Johns Hopkins University Press.

Moniz, Jr, R. J. (2010). Organizational culture and socialization process. in Practical and Effective Management of Libraries. Retrieved from https://www.sciencedirect.com/topics/computer-science/socialization-process

Moody, H. R. (2010). Ageing: Concepts and controversies (6 ${ }^{\text {th }}$ ed.). California: Fine Forge Press.

Moore, D. R., \& McCabe, G. P. (1993). Introduction to the practice of statistics ( $\left.2^{\text {nd }} \mathrm{ed}.\right)$. New York: W.H. Freeman and Company.

Morrin, M., Broniarczyk, S., \& Inman, J.J. (2011). Fund assortments, gender and retirement plan participation. International Journal of Bank Marketing, 29(5), 433450 .

Mutran, E. J., Reitzes, D. C., \& Fernandez, M. E. (1997). Factors that influence attitudes toward retirement. Research on Aging, 19, 251-273.

Nardi, P. (2006). Doing survey research: A guide to quantitative methods. Boston: Pearson.

Noone, J., Alpass, C., \& Stephens, F. M. (2010). Do men and women differ in their retirement planning? Testing a theoretical model of gendered pathways to retirement preparation. Research on Aging, 32(6), 715-38. https://doi. org/10.1177/0164027510383531

Novak, M. (2006). Issues in ageing. Boston: Pearson.

O’Neil, D. (2011). Socialization. Retrieved from https://www2.palomar.edu/anthro/ social/soc_1.htm 


\section{Disaggregation of Gendered Differences in Retirement Planning in Urban Ghana}

Orel, N. A., Ford, R. A., \& Brock, C. (2004). Women's Financial Planning for Retirement: The Impact of Disruptive Life Events. Journal of Women \& Aging, 16(3-4).

Osei-Boateng, C., \& Ampretwum, E. (2011). The informal sector in Ghana. Accra: Friedrich Ebert Stiftung.

Paz, A., Doron, I., \& Tur-Sinai, A. (2018). Gender, aging, and the economics of "active aging": Setting a new research agenda. Journal of Women and Aging, 30(3), 184-203.

Perneger, T. V., Courvoisier, D. S., Hudelson, P. M., \& Gayet-Ageron, A. (2015). Sample size for pre-test of questionnaires. Qual. Life Res. 2, 147-151.

Pescaru, M. (2019). The importance of the socialization process for the integration of the child in the society. Retrieved from https://www.researchgate.net/publication/330076266

Phua, V. C., \& McNally, J. W. (2008). Men planning for retirement: Changing meanings of pre-retirement Planning. Journal of Applied Gerontology, 27(5), 588-606.

Powell, C.A. (1988). Problems and breakdowns of rationality in foreign policy and conflict analysis: A basic review of game theoretic concepts. Peace and Change, https://doi.org/10.1111/j.1468-0130.1988.tb00511.x

Purpura, P. P. (2013). Applicant screening and employee socialization. in Security and Loss Prevention (Sixth Edition). Retrieved from https://www.sciencedirect.com/ topics/computer-science/socialization-process

Quadagno, J. (2002). Ageing and the life course: An introduction to social gerontology. Boston: McGraw Hill.

Quadagno, J. (2014). Ageing and the life course: An introduction to social gerontology (6th ed). Boston: McGraw Hill.

Renzetti, C., Curran, D., \& Maier, S. (2012). Women, Men, and Society (pp. 78-79). Pearson.

Robertson, A. F. (1984). People and the state: an anthropology of planned development. Retrieved from https://agris.fao.org/agris-search/search. do?recordID=XF2015023650 
Robin, F., Dubois, C., Curti, D., \& Schuchmann, H. P. (2011). Effect of wheat bran on the mechanical properties of extruded starchy foams. Food Research International, 44(9), 2880-2888.

Schellenberg, A. Rosehart, W., \& Aguado, J. (2005). Cumulant-based probabilistic optimal power flow (P-OPF) with Gaussian and gamma distributions. IEEE Transactions on Power Systems, 20(2), 773 - 781. https://doi.org/10.1109/TPWRS.2005.846184

Slevin, K.F., \& Wingrove, C.R. (1995). Women in retirement: A review and critique of empirical research since 1976. Sociological Inquiry. https://doi.org/10.1111/ j.1475-682X.1995.tb00404.x

Trewin, J., \& Curatola, A.P. (2002). The inequality of distributions from retirement plans as a result of differing life expectancies. Benefits Quarterly, 18(1), 38-48.

Tsikata, D., \& Darkwah, A. (2014). Researching empowerment: On methodological innovations, pitfalls and challenges. Women s Studies International Forum 45. https://doi.org/10.1016/j.wsif.2014.03.012

Tsikpor, B. (n.d.). Local Governance and Decentralization: An Opportunity for increased WASH service delivery. Retrived from http://www.igs.gov.gh

WHO (2020). Global health observatory. Retrieved from http://www.who.int

Zaidi, A. (2015). Active ageing index: A legacy of the European year 2012 for active ageing and solidarity between generations. In policy brief April 2015. Vienna: European Centre for Social Welfare Policy and Research. 